\title{
LAS COCINAS Y LA COMIDA EN LA OBRA CINEMATOGRÁFICA DE PEDRO ALMODÓVAR
}

\author{
Gerardo Jesús García Olivares \\ Doctor en Industrias Culturales y de la Comunicación. Universitat Politècnica de València.
}

\begin{abstract}
Pedro Almodóvar's cinema has contributed in a veiled way to the construction of the gastronomic identity outside the borders of Spain due to the degree of internationalization that his cinema has. In Almodóvar's cinema, the kitchen as a space is essential to present conflicts, entangle the plot or reach the end. A differentiation can be made between cuisine and food in his cinema, while the kitchen is a marker of classes or customs, the food is transversal to the social conditions of its characters and presents many dishes rooted in a territory. This use of the kitchen and food by the director has contributed enormously to bring the dishes of Spanish gastronomy as a soft power and to the construction of an idea of what is eaten in Spain and where it is made and consumed.
\end{abstract}

Keywords: food, internationalization of culture, food, kitchen, Pedro Almodóvar, cinema.

Resumen: El cine de Pedro Almodóvar a contribuido de manera velada a la construcción de la identidad gastronómica fuera de las fronteras de España debido al grado de internacionalización que tiene su cine. En el cine de Almodóvar la cocina como espacio es fundamental para presentar conflictos, enredar la trama o llegar al desenlace. Se puede hacer una diferenciación entre cocina y comida en su cine. Mientras que la cocina es un marcador de clases o de costumbrismo, la comida es transversal a las condiciones sociales de sus personajes y presenta muchos platos enraizados a un territorio. Este uso de la cocina y la comida por porte del director ha contribuido enormemente a llevar los platos de la gastronomía española a modo de poder suave, así como a la construcción de un ideario sobre qué se come en España y dónde se elabora y se consume.

Palabras clave: comida, internacionalización de la cultura, cocina alimentario, Pedro Almodóvar, cine.

Citar como: Jesús García Olivares, G. (2022). "Las cocinas y la comida en la obra cinematográfica de Pedro Almodóvar". En: Actas del III Congreso Internacional sobre Patrimonio Alimentario y Museos. 25-26 noviembre, 2021, Valencia, España. pp. 217-230. https://doi.org/10.4995/EGEM2021.2021.13405 


\section{Introducción}

El cine del director Pedro Almodóvar ha contribuido de manera velada a la construcción de la identidad gastronómica fuera de las fronteras de España debido al grado de internacionalización que tiene su cine y a la potencia de sus imágenes. Para este director, las cocinas como espacio físico y simbólico son fundamentales en la construcción de sus relatos cinematográficos. En el cine de Almodóvar, la cocina como espacio es imprescindible para presentar conflictos, enredar la trama o llegar al desenlace. Se puede realizar una diferenciación entre cocina y comida. Mientras que la cocina es un marcador de clases o de costumbrismo, la comida es transversal a las condiciones sociales de los personajes que nos presenta. Lleva a cabo constantes referencias a muchos platos enraizados a un territorio determinado.

En este artículo se pretende abordar el uso de la cocina y la comida por parte del director en su amplia producción cinematográfica, y mostrar cómo esto ha contribuido enormemente a llevar los platos de la gastronomía española a modo de poder suave (o como se conoce en inglés powersoft) en el campo de las relaciones internacionales a la influencia en este caso por elementos de componentes culturales como lo puede ser el cine, la literatura, el arte y ahora la comida. El cine de este director ha contribuido enormemente a la construcción de un ideario internacional sobre qué se come en España y dónde se elabora o se consume. También ha servido para mostrar qué platos son propios de determinadas regiones.

\section{Objetivos}

Esta breve comunicación tiene como objetivo mostrar que, a partir del cine, se ha construido una imagen de la cocina como espacio, y se ha mostrado el repertorio culinario cotidiano y la comensalidad de la cultura española. Esta imagen del cocinar y de la cocina ha sido utilizada por el director manchego como un elemento más de su filmografía. Tanto los alimentos sencillos (tortilla de patatas, jamón, flan y otros productos alimenticios) y las cocinas humildes, alicatadas con trozos de azulejos, como las más lujosas, decoradas con piezas de diseño, se muestran, no como un mero decorado, sino como un espacio material pero especialmente simbólico. En estos lugares ocurren situaciones fundamentales que componen la trama de su cine, donde los personajes expondrán sus argumentos, confesarán secretos, serán víctimas de violencia y aplicarán la justicia propia. También serán espacios de encuentro y de enorme humanidad.

La internacionalización del cine de Pedro Almodóvar (con premios como Óscar, Bafta, Globos de Oro, César, entre otros) provoca que también las cocinas y la comida que aparecen en sus películas hayan trascendido los límites de la geografía española. Si dentro del power soft español está posicionar la cocina española como marca España, antes que este objetivo fuera trazado de una manera expresa por los organismos públicos dedicados a ellos como Acción Cultural Española, el cineasta lo lleva haciendo de manera silenciosa desde hace años. Así, el gazpacho, los barquillos y las tapas, las cañas, la tortilla de patatas, el jamón o la paella llegan al panorama internacional de la mano de su cine desde hace décadas.

\section{Desarrollo}

Dentro de la Memoria 2019 de Acción Cultural Española, la entidad pública que acoge las actividades culturales para internacionalizar la cultura española, consta que durante ese año se 
desarrolló un proyecto que aún se puede ver en Google Arts \& Culture, España: cocina abierta, el cual cuenta con la participación de la Real Academia de Gastronomía y el Museo del Traje. En esta plataforma cultural se puede observar una buena muestra de la cocina española y sus protagonistas. Desde las grandes figuras de la restauración hasta la arquitectura del vino. Esto significa que la cocina es un elemento más a internacionalizar de la producción cultural de un país y una forma de softpower de dicho país.

Ese mismo año la cinta Dolor y Gloria no sólo fue seleccionada para competir como película de habla no inglesa ante la Academia de las Artes y Ciencias Cinematográficas de Estado Unidos que concede el premio Óscar, sino que la película se mantuvo por semanas en cartel en ese país. En la quinta semana, según la empresa de marketing digital ComScore acumulaba más de dos millones de dólares de recaudación y se mantenía en cartel en 111 cines. En esta película, los protagonistas comen jamón de la misma manera que en otras de sus cintas consumen tortilla de patata o paella. Esto muestra la importancia del papel de la cocina en su cine y como este está construyendo una representación del modo de comer en España.

Este gran escaparate visual que es el cine de Pedro Almodóvar en el plano internacional también lo es para las cocinas y los platos que en él se reflejan. Ya en 1988 con la candidatura por la Academia de Artes y Ciencias Cinematográficas de Estados Unidos, conocida en inglés como AMPAS (Academy of Motion Picture Arts and Sciences), la mítica receta de gazpacho descrita por Carmen Maura había llegado a Estados Unidos. Consiguiendo, así, incorporarla en el imaginario gastronómico español que el director refleja con su cine.

Desde los orígenes de la filmografía de Pedro Almodóvar, los alimentos son un elemento profundamente plástico. Esto puede verse en el cortometraje Salomé, donde recurre germinalmente a la comida en el título, ya que el mismo está realizado con tipografías obtenidas a partir de una sencilla sopa de letras y estrellas. El resto de los créditos están hechos de masa horneada y, en ellos, se pueden apreciar estrellas bañadas de chocolate. Al parecer este es el mismo material que utiliza en el título principal del cortometraje.

Para Pedro Almodóvar las escenas que transcurren en la cocina contribuyen a tensar el argumento y enriquecer la trama. No solo los alimentos, sino la forma de adquirirlos. El cine de Pedro Almodóvar refleja la vida de las mujeres españolas. Por este motivo, los mercados también aparecen retratados en sus películas. Esto se ve, por ejemplo, en la conversación sobre el patatas que tienen las vecinas protagonistas de Pepi, Luci, Bom y otras chicas del montón (1980). En este filme también se pude ver como se prepara un plato tradicional: el bacalao al pil pil.

Laberinto de pasiones (1982) quizá sea una de las películas en donde la alimentación está menos presente de forma específica. Sin embargo, hay claras referencias a los bares y las terrazas como forma de comensalidad española. Corrían los años de lo que se conoció como el "pelotazo", en donde el lujo se extendía a muchas clases sociales. Era más común comer fuera que en casa, por eso en su cine los personajes disfrutan de restaurantes y terrazas. Estas últimas no solo son un espacio de alimentación, sino que también son la extensión culinaria de la casa y la representación del acto de tomar el fresco propio de la zona mediterránea. En estas zonas las altas temperaturas nocturnas provocan que las personas compartan comida en un entorno abierto más agradable. Además, se trata de nuestra forma de comida callejera en un entorno socioeconómico óptimo. 
En la anticlerical Entre tinieblas (1982) comienza a aflorar su paleta colorista. Por momentos, en su cine, hay instantes de puro costumbrismo y el color se adueña de la pantalla con frutas escarchadas de los pasteles elaborados por la rocambolesca Congregación de las Esclavas Redimidas para recolectar fondos. El diacitrón o cidra era, en los siglos XVI y XVII, un dulce que además tenía valor medicinal. También se trataba de un regalo que se daba a monarcas y a reyes. La fruta escarchada es un tema muy recurrente en la pintura de bodegones, ya que era propia su producción en la España de ese tiempo. Las monjas la usaban para decorar sus postres. En la película se pueden ver algunas prácticas que todavía es posible observar en algunos bares, como la de anunciar con dibujos y textos en tiza las especialidades de la casa y la carta. Este trabajo era un oficio y lo realizaban personas que se trasladaban de ciudad a ciudad a cambio de una pequeña retribución.

En la película hay una clara referencia a unos de los productos más conocidos de la charcutería española. Se trata del chorizo de Cantimpalo de la homónima localidad Segoviana, que cuenta con la IGP (Indicación Geográfica Protegida). Este aparece cuando la Madre Superiora del convento, que es adicta al crack, le da la lista de las cosas que comprar a una de la monjas de menor rango.

No es extraño que, dentro de la trama, la cocina esté tan presente y que las protagonistas ofrezcan algunos de sus productos en el Rastro de Madrid. Esto demuestra que la cocina conventual es aún una realidad viva en España y que todavía permanece en los cientos de obradores que ofrecen sus productos. Alguno, incluso, comercializándolos por internet. Además de esta comida, en la cinta se observan las tradicionales latas de galletas Guillón, así como la sangría (otro coctel muy extendido en nuestro país) en la escena de la fiesta que da la Madre Superiora y que finaliza la película.

De 1984, con claras referencias al neorrealismo italiano, es la película ¿Qué he hecho yo para merecer esto? El director elige el producto más emblemático de la gastronomía española, el jamón, para transformarlo en un elemento de defensa. Gloria lo usa como objeto contundente, para defenderse de las agresiones machistas que le da su marido, un desgastado jamón del que solo queda el hueso. Además del jamón, aparecen alimentos muy arraigados a la cultura alimentaria española, como el Agua de Vichy o el bocadillo de tomate frito. Este último se presenta como último recurso alimentario en una familia de escasos recursos que habita en el suburbio de Madrid.

La cocina, como espacio sofocante y decisivo, es un emblema en la cinematografía de Pedro Almodóvar y un excelente escenario para algunas escenas de crímenes. Bien porque cuentan con objetos que pueden ser auténticas armas como cuchillos (es el caso de Volver), o bien el mismo hueso de jamón de ¿Qué he hecho yo para merecer esto?

En todo su cine las paredes no son solo un elemento donde los actores interpretaran a sus papeles, sino una expresión y testigo de la moda, colores y materiales de la época. El empapelado de las cocinas, que no se contaban con azulejos, era una práctica recurrente en las viviendas humildes. Las propias mujeres las cambiaban habitualmente. Es posible decir que, en cuanto a la dirección de arte en Almodóvar, tantos las paredes como los suelos no pasan inadvertidos, sino que adquieren un protagonismo y le aportan identidad a los personajes.

En la película, también pueden verse los armarios de cocina de la marca Forlady, que una niña con poderes telequinéticos moverá cuando ayude a empapelar la cocina a Gloria. El nombre 


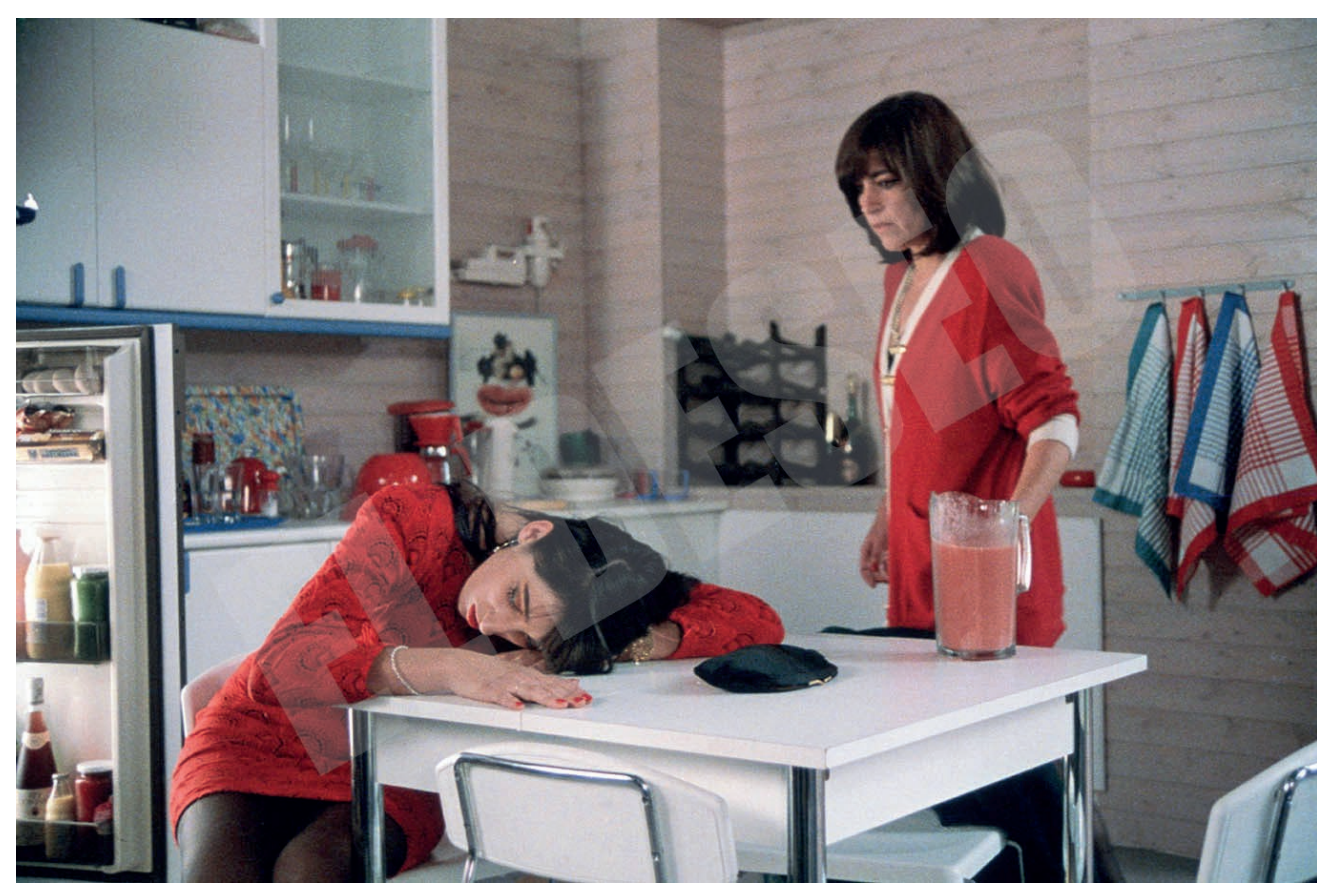

Figura 1. Fotograma del filme Mujeres al Borde de un ataque de nervios - 1988 - El Deseo.

en inglés de estos armarios lleva una velada referencia al papel de las mujeres del momento. Su papel como amas de casa era casi una condición obligada y carecían de derechos. Por ejemplo, abrir una cuenta bancaria sin la autorización de su esposo no fue posible hasta 1978. Estos armarios se popularizaron a partir del año 1967, sobre todo acompañando a las vivienda de carácter social. Los muebles de cocina Forlady, un referente en el sector de la decoración, se posicionaron en 1967 y llegaron a tener su propia línea de juguetes para niñas comercializados por la marca Payá.

No libre de polémicas estuvo marcada Matador de 1986. En esta película abordaba, como en otras tantas obras de su cinematografía, la violencia de género cuando en España el tema todavía era tabú. En Matador podemos ver a una madre clerical que comparte con su hijo, previa bendición, una sopa de fideos, un lenguado meunière y un flan. Este postre será uno de los platos que estará presente en la mayoría de su producción posterior.

La cocina adquiere importancia, aún cuando no hay comida, en la cinematografía de Pedro Almodóvar en La Ley del Deseo del año 1987. Carmen Maura come frugalmente una rodaja de salchichón. Va a la casa de su hermano Pablo, cineasta, y lava los platos sucios de una cocina. En la película, como en otras del director, el homenaje al artista Edward Hopper es evidente; ya sus personajes deambulan en restaurante, bares y sitios de comida rápida como los que retrataba el pintor. En este caso se pueden apreciar refrescos y otras comidas rápidas desperdigadas en le mesa. La gran presencia de bares en la película refuerza el cliché del número de locales de este tipo en nuestro país. 
El diseño gráfico es otras de las obsesiones del cineasta. En este caso relacionado con los alimentos que aparecen en las etiquetas de marcas emblemáticas de bebidas españolas como Osborne o Freixenet, así como la etiqueta de Anís la Castellana. El espectador puede observar esta última en la trastienda del bar donde los personajes debaten sobre un guion de cine. Los personajes pasan de puntilla sobre la comida, ensaladas, sándwich tostadas y desayunos porque lo que importa no es la comida, sino la bebida.

Los cambios sociales que vivía España en los años que se rodó en la Ley del Deseo se ponen de manifiesto en la película por medio de escena en donde se puede ver el primer Burger King que se inauguró en España en la plaza de los Cubos en Madrid. La marca llevaba solo diez años en el país y en esos años de bonanza también abrió el primer McDonald’s en 1981. Los hábitos alimentarios de los españoles estaban cambiando.

El gazpacho otro plato internacionalizado de la cocina española y que hoy se puede apreciar como ejemplo en restaurantes de tapas de Los Ángeles se da cita en Mujeres al borde de un ataque de nervios rodada en 1988. Como se comentó al principio del artículo la protagonista describe ante la policía cada uno de los ingredientes de la receta omitiendo los morfidales un potente somnífero que la protagonista quiere camuflar en esta sopa fría para que su expareja se duerma en casa y poder hablar con él. La misma Tilda Swinton iba recordar que adoraba beber gazpacho durante el rodaje The Human Voice de 2020 en el video de presentación que acompaña a su último cortometraje rodado en plena pandemia.

La comida y las cocinas está presente en todas sus películas y es uno de los grandes embajadores de España, ya que ha llevado platos de la comida de las clases populares, y hasta platos de los más regionales, al centro de la pantalla. La comida menos patrimonializada, pero la más arraigada a determinadas identidades y repertorios locales, se puede ver en su cine. En ¡Átame! de 1989 hace clara referencias a las sociedades gastronómicas tan presente en la cultura vasca, el comprar el turrón por gramos en la tienda de dulce. Un poco de costumbrismo que rivaliza con productos dulces industriales. Algunos ejemplos de ello son los Blody Mary que curan la resaca y el pisto ofrecido como cocina casera que añora Marina (interpretada por Victoria Abril) y que elabora en la pantalla la misma madre del director en un lebrillo de cerámica. 0 el desayuno que Ricki le ofrece de zumo, yogur y frutas; otra de las identidades alimentarias españolas. Vale la pena recordar que la mezcla de café (con leche o sin ella), el pan acompañado de tomate, aceite de oliva o mermelada y mantequilla, y el zumo o la pieza de fruta es un desayuno propio de la patrimonializada dieta mediterránea.

Tacones Lejanos rodada en el año 1991, que obtuvo el Cesar a mejor película extranjera, es una de las cintas del director donde menos presente esta la comida, quizás por que el personaje principal Becki del Páramo no ha vivido en España durante años. No aparecen cocinas, sino mesas en donde se come de manera frugal. Totalmente colorista, se apuesta por alimentos que componen bodegones en fruteros de mesas para dar color a las escenas. Uno de los principales detalles es la presencia de un bocadillo de pasta de avellanas, conocida bajo la marca comercial Nocilla, que Rebeca merienda siendo niña. La mezcla de chocolate en pan ha sido una de las meriendas más difundidas en la alimentación española. Junto con el pan con chocolate que retoma en Dolor y gloria, como se detallará luego.

En Kika de 1993 llegamos a la cocina colorista, folclorizada, cargada de objetos como la olla a presión, la aceitera, las piezas de cerámica, las cortinas a cuadros, los fruteros, el utillaje y los 


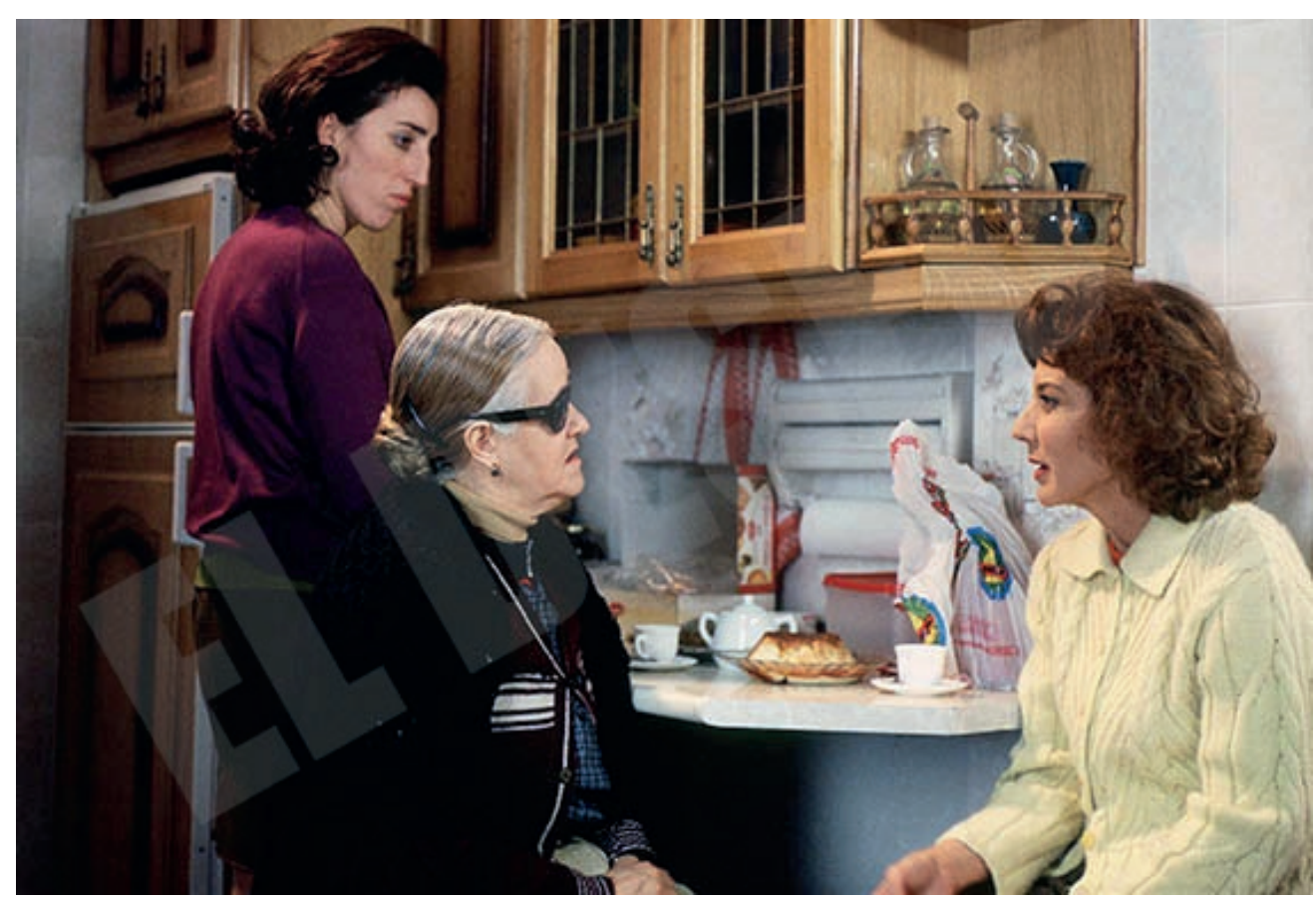

Figura 2. Fotograma del filme La flor de mi secreto - 1995 - El Deseo.

paños de cocina que cuelgan de las paredes, que luego repetirá en otras de sus cintas. En este caso, la cocina es el lugar preferido para perpetrar una simulación de secuestro y es fundamental en la trama.

La paella, el plato español por excelencia y emblema de la gastronomía española, aparece en el film La flor de mi secreto del año 1995. Este plato es el gran protagonista culinario de la película y el que completa la triada: tortilla, paella y gazpacho. Platos que se pueden ver en esta como en otras películas. Y que se complementan con las berenjenas de Almagro, producto de la localidad que, al final de la cinta, un corro de encajeras de bolillo menciona en una canción. Además, la paella desencadena una discusión a causa de la diferencia de opiniones que tienen los protagonistas sobre su temperatura.

En esta película, tiene lugar uno de los diálogos más potentes del cine del director. Entre el costumbrismo y el teatro, se encuentra la pequeña cocina de Rosa que vive en el extrarradio de Madrid. Este diálogo hace referencia a la cocina misma española, la cafetera italiana, los calamares a la romana, el flan casero que es un talismán en el cine del director, y los pimientos que la madre interpretada por Chuz Lampreave ha asado a su hija.

Pedro Almodóvar recurre a la cocina como metáfora de la pasión en la película Carne Trémula de 1997. La chabola donde vive el joven Víctor, interpretado por Liberto Raval, arde hasta consumirse por culpa de una sartén puesta al fuego por Ángela Molina, en el papel de Clara. Las cocinas de su cine están llenas de color, construyendo un espacio luminoso en donde lo femenino fluye. No son un espacio de confinamiento o reclusión de lo femenino, sino como los 
gineceos de la antigua Grecia. El lugar en donde las mujeres podrán expresar sus emociones y donde los hombres no aparecen y, si lo hacen, invaden la tranquilidad de la cocina con una marcada masculinidad estereotipada por el machismo o la masculinidad tóxica. En esta película un hombre violento trata de resarcirse cocinando rabo de toro al brandy y terminará matando a su propia esposa.

Esta cocina, como la de Kika o Volver, se muestra como un espacio tradicional de donde penden morcillas o pimientos y enceres ya en desuso. Sin embargo, marcan el espacio transformándolo en algo anticuado y, en algunos casos, los objetos se convierten en coloristas rondando lo camp.

La esqueixada es el plato elegido por el cineasta en Todo sobre mi madre de 1999, filme con el que ganaría el Óscar a mejor película extranjera. Este plato, propio de la gastronomía catalana, lo pide la actriz Huma Rojo después de cada representación. Es un plato ligero, fresco a base de pescado cebolla, pimiento y tomate. La comida no adquiere gran importancia en la película, pero sí las cocinas y la mesa donde se debatirán algunos de los diálogos más importantes que componen la trama. Nos moveremos desde la cocina viva, colorida y luminosa (donde Manuela, el personaje principal, servirá frugales ensaladas a su hijo en Madrid) a la lúgubre cocina con reminiscencia de los 70 de la casa precaria donde se irá a vivir en Barcelona. En ella come productos envasados, a modo de alimentación de subsistencia, debido al dolor por el que atraviesa el personaje. Se reconoce todo el tiempo la bondades culinarias de Manuela, pero no se observa que las ponga de manifiesto salvo en casos puntuales. Ella muestra su duelo por medio de la comida, salvo en algún momento donde los personajes beben cava; otra bebida puramente española.

En la cinta Hable con ella del 2002, nominada en dos categorías a los Óscar por mejor director y guion original, la cocina será el lugar en el que se puede escuchar un grito (como si de una película de Hitchcock se tratara) cuando la protagonista encuentra una culebra y convence al otro protagonista masculino para que le de muerte. Así, la cocina es el espacio donde se pone de manifiesto una de las supersticiones de Lydia González, protagonizada por Rosario Flores, que anticipará el fatal desenlace de la torera.

Como si de una matrioshka se tratase, dentro de la película aparece otro filme, un claro homenaje al cine mudo y a la película The Incredible Shrinking Man de 1957. En El increíble hombre menguante de Almodóvar, la cocina también está presente. Ya no como espacio o como alimento, sino como experimento científico. Amparo, la protagonista de este cortometraje, está investigando una sustancia que será una revolución en el mundo de la nutrición. Al ser ingerida en un acto de heroicidad desafiante, desencadenará que el protagonista comience a menguar hasta hacerse diminuto y poder entrar en el cuerpo de ella.

Los personajes beben cerveza en formato de caña, una de las formas de beber cerveza que compite en popularidad con las pintas británicas. Otra referencia a la cocina española son las imágenes de los extensos paisajes de olivos de Córdoba, que rodean a la Ermita de Nuestra Señora de Araceli de Lucena. Viene bien recordar que España es el primer país a nivel mundial dedicado a este cultivo y que el aceite de oliva es uno de los productos más destacados de la culinaria española.

Las ciudades españolas están marcadas por la migración. Esto lo sabe bien Pedro Almodóvar, quien migró desde su Calzada de Calatrava natal a Madrid. Lo primero que llevan los migrantes a su nueva residencia es su propio repertorio culinario y esto está presente en la filmografía del 


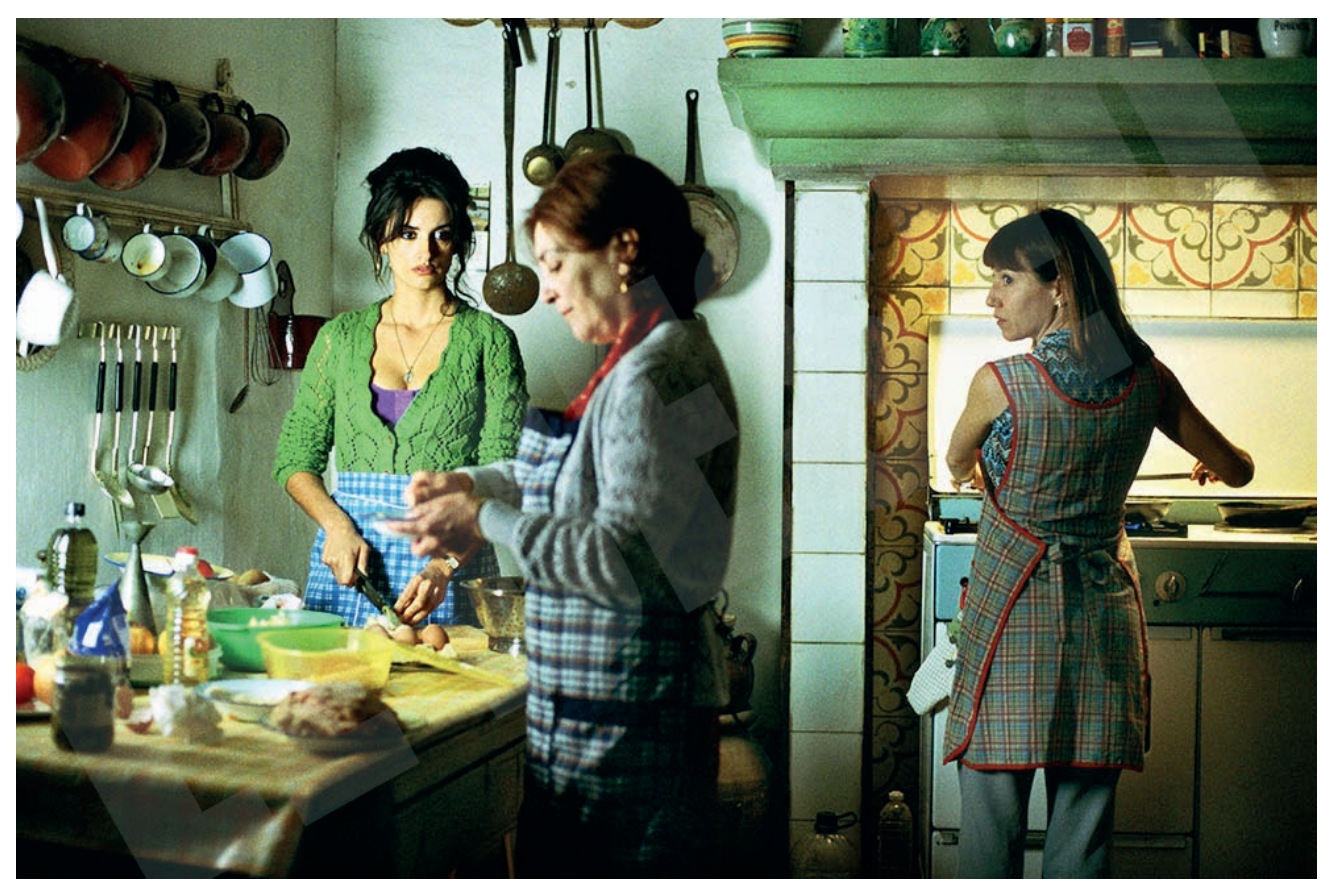

Figura 3. Fotograma del filme Volver - 2006 - El Deseo.

director. Los lazos con el pueblo de origen se mantienen y se manifiestan en la dieta. Los migrados suelen incorporar productos que traen del pueblo cada vez que lo visitan, como narra en La flor de mi secreto o Volver.

En La mala educación de 2004 el actor Francisco Boira da vida al personaje de Juan, un transexual que ha migrado de un pueblo de Galicia a Valencia. En una de sus visitas a su localidad natal se pueden ver algunas verduras depositadas en el pajar sobre periódicos viejos, a modo de conservación. Al regresar de visitar a su madre, llevará del pueblo quesos y chorizos. En la cinta se pueden apreciar bodegones en fruteros, los cuales aportan el color propio de las películas del director.

También hace hincapié en la comida del internado en donde pasa su infancia el protagonista. En él tiene una lugar una potente imagen, que recuerda a San Hugo en el Reflectorio hacia 1655 de Zurbaran, cuando los padres de la congregación rodean la mesa mientras el niño Ignacio canta por motivo del cumpleaños del padre director.

Volver, junto con La flor de mi secreto y la recientemente estrenada Madres Pararelas (2021), es la película donde existen más referencias a la comida, a las cocinas y la forma de comer. En esta película del año 2006, ganadora de dos Globos de Oro, aparecen barquillos, lomo con pimientos y rosquillas. Se vuelve a hacer referencia a uno de los platos de la Mancha, que las protagonistas llevarán en cajas de plástico perfectamente señalizadas a la ciudad luego de una visita al pueblo por el día de muertos. Esta vez, una madre, confundida con un fantasma, será la que prepare las viandas. 
Raimunda protagonizada por Penélope Cruz se verá afectada por unas trágicas circunstancias ocurridas en una cocina mientras gestiona un restaurante. Para solucionarlo pedirá ayuda a las vecinas y preparará un menú del día, algo propio en la cocina española. El menú (formado por morcillas, mantecados y lomo cedido por las vecinas y traído del pueblo) será la primera comida que consumirá en su restaurante un equipo de producción.

En Los abrazos rotos de 2009 la cocina, se presenta como espacio de confesiones en donde los protagonistas establecen diálogos clarificadores de la historia principal o se plantean conflictos. El gran protagonista es el desayuno: zumo de naranja café, leche, frutas, las tostadas con aceite; el desayuno mediterráneo por excelencia.

Finalmente, tal y como pasa en otras películas, el protagonista monta Chicas y maletas. Se trata de una película apócrifa que es, a su vez, una película dentro de la propia película. Aquí el flan y las magdalenas también son mecionados.

La cocina como espacio panóptico, desde donde se puede controlar las acciones de todo lo que ocurre en la casa, lo podemos encontrar en La piel que habito de 2011. Como en Volver, los cuchillos de gran tamaño van presagiando el fatal desenlace que tendrán algunos personajes. Marilia, desde la cocina, vigilará con videocámaras todo lo que ocurre en la casa y cada mañana, durante el desayuno, hormonará a Vera, interpretada por Elena Anaya. Finalmente, entre los cajones de la cocina se esconde la pistola que dará muerte a su propio hijo.

El agua de Valencia, cuyo origen se remonta a 1959, aparece en Los amantes pasajeros de 2013. Aunque la película transcurre en un avión, aparecen elementos del repertorio gastronómico, como este coctel, el cual cuenta con ingredientes como el zumo de naranja, la ginebra, el vodka, el azúcar y el cava. La tripulación lo reparte entre los pasajeros, después de haberle agregado somníferos para dormirlos ante un inminente accidente aéreo. La comida se hace presente en su cine, aún cuando por razones de espacio no puede elaborarse o se prepara en la diminuta cocina de un avión.

En el año 2016 Almodóvar rueda Julieta. En el filme, el personaje, angustiado por la ausencia de su hija, va marcando el paso del tiempo con las tartas de cumpleaños que tira a la basura cada año en que su hija está ausente. En toda la dirección de arte de sus filmes es posible apreciar objetos que acompañan a los personajes, que dan identidad y suponen su historia personal. No son objetos colocados solo como attrezzo, sino que componen al personaje.

Almodóvar, gran amante de las piezas de cristal que el mismo colecciona y con las que construye bodegones que después fotografía, también es amante de la cerámica. Esto se manifiesta en cada una de sus películas a través de suelos, estanterías y paredes; así como con piezas de cerámicas que los personajes utilizarán para beber, comer o, incluso, de lapiceros. En Julieta podemos ver referencias a diversos artistas. Al igual que en otras cintas como en La piel que habito, en donde se puede ver obras de Louise Bourgeois, o en Dolor y gloria con los Pérez Villalta. En el caso de Julieta, la referencia a artistas españoles llega de la mano de Miquel Navarro con una escultura, El hombre sentado, elaborada por uno de los personajes.

La cerámica se encuentra en piezas de la casa Sargadelos, la cual aparecerá en muchas de sus películas. En esta casa, afincada en Galicia, donde transcurre parte del guion, se elabora cerámica desde principios del siglo XIX. En el filme, la cerámica acompaña al personaje principal, ya que se pueden ver las mismas piezas en las distintas viviendas que irá teniendo. También 
se aprecian de azulejos con motivos marinos y un extraordinario botijo con forma de sandia en el centro de la mesa que acompañará una conversación clave en el guion entre dos de los personajes. Esta pieza originaria, seguramente, de la localidad de Manises o de Talavera, hoy día considerada Patrimonio de la Humanidad Cerámica, que compone lo que se llamo cerámica de engaño propio del siglo XVIII y que se popularizó a mediados de los 50 como piezas decorativas de las casa populares.

En Julieta, la cocina es casi un faro desde donde se puede ver el mar. Se trata de un espacio colorista desde donde podrá observar el estado del mar ante una de las tragedias que acontecen en la trama. Por otro lado, la casa donde vive el padre también recurre a la cocina como espacio tradicional. Junto a ella hay una huerta donde el hombre produce sus propias hortalizas y elabora las conservas que se pueden ver en los armarios.

En Dolor y gloria del año 2020, ya podemos ver al Almodóvar actual. Muestra, a modo de contraste, la cocina de diseño que el personaje de Salvador Mallo tiene de mayor. Desde ella, rememora la casa-cueva de su infancia, en la localidad valenciana de Paterna. Se presenta como cine dentro de cine disfrazado de recuerdo. En la cocina actual, los electrodomésticos más modernos y tecnológicos se camuflan entre coloridas paredes y obras de arte. Estas también usan la comida como elemento plástico, es el caso de obra de Maruja Mallo: Racimo de Uva de 1944. El personaje tiene problemas digestivos por lo que la comida que aparece son platos de jamón, el omnipresente flan y tortillas de huevos. Además, su asistente personal le pide a su cocinera que le triture la comida, debido a su dolencia, mientras pela patatas. En la cocina se pueden observar algunos de los bodegones que el mismo Pedro Almodóvar ha creado y fotografiado.

En contrastaste con esta cocina, la comida de la infancia de la que habla el director hace referencia al pan y su elevado precio en la España del racionamiento. Durante el filme se pude apreciar como la cocina de la casa-cueva va adquiriendo forma y color. Pasa de ser un espacio inhóspito a uno lleno de vida, donde se mostrará una técnica utilizada por la construcción popular consistente en el aprovechamiento de restos de azulejos de casas nobles para alicatar cocinas y baños. En la cocina de Jacinta, de donde pende una bombilla que recuerda al Guernica de Picassso, comerán magdalenas, le ofrecerá una tortilla de patatas o se beberá zumo de naranja; un producto propio del levante donde se ambienta esa parte de la historia. Amante el director de los elementos gráficos, se muestran latas de aceite, pimentón u olivas que se reciclan como macetas de geranios y humanizan la vida en la casa-cueva.

Jacinta de mayor le reprochará al hijo, cuando este le pide que coma unas magdalenas integrales, que estas carecen de valor por su aspecto "renegridas". Con ello el director pone de manifiesto los cambios que estamos viviendo en la alimentación contemporánea. El mismo papel tiene el muffin de arándanos que comerá un de los personajes en su última película.

En el cortometraje La voz humana de 2020, no hay comida pero sí varias escenas que trascurren, como en todo el cine de Pedro Almodóvar, en la cocina. Una cocina inerte, de escaparate, rodeada de objetos de diseño. Un espacio casi traumático como el diálogo de Cocteau, en el que la soledad y la angustia del personaje se ven reflejados en los electrodomésticos y elementos de la cocina. No hay comida, el aspecto es de una habitación lujosa, pero totalmente inhóspita.

En la cinta Madres paralelas, estrenada el 8 de octubre de 2021, la cocina volverá a formar parte vital de la vida de los personajes. Se retoma la cocina como escenario en el que se realizan confesiones, se establecen conflictos y se presenta la naturaleza de los personajes. Durante 
toda la película aparecen alimentos como la tortilla de patatas, las morcillas y los pasteles. Los barquillos y las flores se convierten en marca de identidad de la ruralidad que quiere transmitir el director. Esto se aprecia cuando visitan a Arturo, el antropólogo forense interpretado por Israel Eljalde, y Janis, el personaje de Penélope Cruz. Acuden a una casa situada en una localidad donde van a exhumar una fosa común con restos de fusilados por el franquismo. La vivienda denota esencialidad rural, pero con color, luz y brillo: morteros, botijos, cocinas de mampostería, fruteros, especieros, jamones a medio consumir y estanterías con cortinas en lugar de armarios.

\section{Resultados}

Tras el el análisis de toda la filmografía del director Pedro Almodóvar (compuesta por 22 películas y 2 cortometrajes) se puede apreciar que en su cine se diferencia entre cocina y comida. La cocina será, en un número importante de ocasiones, el espacio y contexto simbólico donde se desarrollen elementos de la trama que darán vida a cada una de las películas. En sus cocinas, podremos descifrar la condición social de sus personajes. Por otro lado, la comida será lo que se muestre como forma de identidad local, defina los personales de los personales o señale las restricciones alimentarias por salud de los mismos.

La cocina, ya sea la más rural o la más vanguardista, donde aparecen piezas de diseño mezcladas con obras de arte, mostrará al espectador qué comen y cómo se come. Se convierte es una forma de transmitir al espectador no solo la naturaleza y la vida social, sino también la intimidad de los personajes. Los objetos que adornan las cocinas hablan de ellos, de su devenir. No son objetos que se muestren como mero atrezo, sino que se verán como parte de sus gustos personales. También se apreciará si hay alimentos a medio consumir, tapados o preparados para ser consumidos.

A diferencia con la cocina, donde se aprecia el condicionante de clase social mostrando espacios lujosos y otros extremadamente humildes, en la comida se apreciará cierta transversalidad a través de los platos. Veremos si son comidos por personas de clases acomodadas o más humildes, pero, donde más se marca la diferencia es entre la comida de diferentes localidades. Cada ciudad tiene un repertorio de platos que le son propios como los barquillos y rosquilletas de la Mancha, las tostadas con tomates de Andalucía o la esqueixada de Cataluña. Tal y como pasa en la actualidad, si bien hay unos repertorios gastronómicos pertenecientes a la Alta Cultura, existen otros que no reconocen condición social como la paella, la tortilla de patatas o el jamón entre otros.

\section{Conclusiones}

De la misma manera que en otros cines (como en el italiano, el francés o el americano) la comida da carácter, naturaliza a los personajes con comidas como la pasta, una baguete o batidos y hamburguesas, respectivamente; en el cine de Pedro Almodóvar hay una diferenciación entre cocina y comida. Sin embargo, ambas construyen una identidad visual y alimentaria que el director lleva a la pantalla y que impele de manera internacional. La cocina española (cocina y comida) se replica en otras partes del mundo de la mano del turismo, de cocineros españoles de reconocida trayectoria internacional y también del cine. Así la cocina se transforma en esa manera de poder suave cultural que el país traslada al plano internacional. 
La construcción de la identidad alimentaria se realiza con las diferentes capas del sistema alimentario. Desde las más periféricas, como la comida rápida en manos de multinacionales, hasta la comida más tradicional que se a diarios se cocina en cada casa. El cine, en general, permite la construcción de un ideario alimentario de un país. Por escenas del cine de Yasujiuro Ozu hemos podido aprender las formas de comer en Japón. Por Fellini la trascendencia que la pizza y la pasta tienen en la gastronomía italiana y mundial. $Y$ en el caso de un director como es Pedro Almodóvar (en que su cine ha recibido 2 Óscar, 5 Bafta, 2 Globos de Oro, 2 en Festival de Cannes, 2 en el de Venecia en el que se incluye el de honor a su trayectoria además de los 10 Goya, entre otros) sirve para reflexionar sobre cómo su cine sitúa a la comida española en el panorama internacional al nivel de los ejemplos antes citados. La cocina como espacio y la comida como marcador de identidad se percibe en la presencia de nuestra comida en culturas alimentarias que distan de la alimentación mediterránea. Lo que convierte a su cine en un excelente embajador culinario de este país.

\section{Bibliografía}

\section{Libro}

Almodóvar, P., \& Strauss, F. (2001). Conversaciones con Pedro Almodovar. Madrid: Ediciones AKAL.

Duncan P., Peiró B. (2013). Los Archivos de Pedro Almodóvar. Cologne, Taschen.

Méjean, J. M. (2007). Pedro Almodóvar. Barcelona: Ediciones Robinbook.

\section{Página web}

Google \& Arts España cocina abierta. < https://artsandculture.google.com/project/spanishgastronomy> [Consulta 19 de octubre de 2021]

\section{Películas}

Pepi, Luci y Bom y otras chicas del montón (Dir. Pedro Almodovar). [DVD]. Ester Rambal Coromina. 1980.

Laberinto de Pasiones (Dir. Pedro Almodovar). [DVD]. Musidora. 1982.

Entre tinieblas (Dir. Pedro Almodovar). [DVD]. Tesauro. 1983.

¿Qué he hecho yo para merecer esto ? (Dir. Pedro Almodovar). [DVD]. Tesauro. 1984.

Matador (Dir. Pedro Almodovar). [DVD]. Lolafilms. 1986.

La Ley del deseo (Dir. Pedro Almodovar). [DVD]. El Deseo. 1987.

Mujeres al borde de un ataque de nervios (Dir. Pedro Almodovar). [DVD]. El Deseo. 1988.

¡Átame! (Dir. Pedro Almodovar). [DVD]. El Deseo. 1989.

Tacones Lejanos (Dir. Pedro Almodovar). [DVD]. Canal + y El Deseo. 1991.

Kika (Dir. Pedro Almodovar). [DVD]. Ciby 2000. 1993.

La Flor de mi Secreto (Dir. Pedro Almodovar). [DVD]. El Deseo. 1995. 
Carne Trémula (Dir. Pedro Almodovar). [DVD]. El Deseo, Ciby 2000 y France 3 Cinéma. 1997.

Todo sobre mi madre (Dir. Pedro Almodovar). [DVD]. El Deseo, Renn Productions, France 2 Cinéma y Vía Digita. 1999.

Hable con ella (Dir. Pedro Almodovar). [DVD]. El Deseo. 2002.

La mala educación (Dir. Pedro Almodovar). [DVD]. El Deseo. 2004.

Volver (Dir. Pedro Almodovar). [DVD]. El Deseo. 2006.

Los abrazos rotos (Dir. Pedro Almodovar). [DVD]. El Deseo. 2009.

La piel que habito (Dir. Pedro Almodovar). [DVD]. El Deseo, Blue Haze Entertaimnment, Canal+ España, Televisión Española, ICAA y FilmNation Entertainment. 2011.

Los amantes pasajeros (Dir. Pedro Almodovar). [Netflix]. El Deseo, Renn Productions y France 2 Cinéma. 2013.

Julieta (Dir. Pedro Almodovar). [Filmin]. El Deseo. 2016.

Dolor y gloria (Dir. Pedro Almodovar). [Netflix]. El Deseo. 2019.

La voz humana (Dir. Pedro Almodovar). [Filmin]. El Deseo. 2020.

Madres Paralelas (Dir. Pedro Almodovar). [Sony Picture]. El Deseo, Sony Pictures, RTV Remotamente Films. 2021.

\section{Vídeo de Internet (Youtube, Vimeo...)}

Salome Youtube < https://www.youtube.com/watch?v=1FJW6BbcjFQ\&t=73s > [Consulta: 18 de octubre de 2021] 